\title{
Microwave Sensor Technologies for Food Evaluation and Analysis - Methods, Challenges and Solutions
}

DOI:

10.1177/0142331217721968

\section{Document Version}

Accepted author manuscript

Link to publication record in Manchester Research Explorer

\section{Citation for published version (APA):}

Meng, Z., Wu, Z., \& Gray, J. (2017). Microwave Sensor Technologies for Food Evaluation and Analysis - Methods, Challenges and Solutions. Transactions of the Institute of Measurement and Control.

https://doi.org/10.1177/0142331217721968

\section{Published in:}

Transactions of the Institute of Measurement and Control

\section{Citing this paper}

Please note that where the full-text provided on Manchester Research Explorer is the Author Accepted Manuscript or Proof version this may differ from the final Published version. If citing, it is advised that you check and use the publisher's definitive version.

\section{General rights}

Copyright and moral rights for the publications made accessible in the Research Explorer are retained by the authors and/or other copyright owners and it is a condition of accessing publications that users recognise and abide by the legal requirements associated with these rights.

\section{Takedown policy}

If you believe that this document breaches copyright please refer to the University of Manchester's Takedown Procedures [http://man.ac.uk/04Y6Bo] or contact uml.scholarlycommunications@manchester.ac.uk providing relevant details, so we can investigate your claim.

\section{OPEN ACCESS}




\title{
Microwave Sensor Technologies for Food Evaluation and Analysis - Methods, Challenges and Solutions
}

\author{
Zhaozong Meng, Zhipeng Wu, and John Gray
}

\begin{abstract}
Microwave sensor technology is widely accepted as a non-destructive and hygienic means for food evaluation and analysis. However, its applications concentrate on in-lab investigations, which are not widely applied for on-line measurement in food industry. Motivated by the rapid progress of microwave technologies and the lack of on-line measurement systems in industry, this paper aims to provide a comprehensive overview of microwave sensors for food measurement, define the technological gap, and suggest the potential solutions. With a brief introduction to the fundamentals, classification and analysis of the traditional methods and technologies are presented, followed by a discussion of calibration and decision-making methods. Based on the analysis of the cutting-edge microwave sensing technologies, the limitations and challenges facing the present studies are identified. Then, focusing on some new emerging technologies including Monolithic Microwave Integrated Circuits (MMIC), antenna array, and System on Chip (SoC) Ultra-Wide Band (UWB) pulse-based time domain systems, the feasibility and prospective of potential solutions in this particular area are suggested. In addition, integration of emerging Information and Communication Technologies (ICT) and new design concepts of the sensor system concerning the practical use for smart manufacturing are also illustrated. The potentiality of the suggested new emerging technologies and integration of ICT to satisfy future digitised industry will be inspirational and of interest to researchers of both microwave engineering and food sectors.
\end{abstract}

\section{Keywords}

Microwave Sensor, food industry, food quality evaluation, dielectric properties, frequency/time domain

\section{Introduction}

Food quality and food composition are key parametersat all stages of food manufacturing industry. The theories and instruments for food evaluation by determining the dielectric properties and dielectric behaviours have been of interest for many years (Nelson 2006;Venkatesh and Raghavan 2004). Microwave sensor outperforms other peer technologies in several aspects including being non-destructive, capable of inspecting the internal, and non-contamination. Therefore, it has been extensively investigated to determine certain properties of food materials by measuring permittivity in a variety of applications (Gabriel et al. 1996;Schimmer et al. 2004). Due to the wide frequencyrange of microwave (300MHz$300 \mathrm{GHz}$ ), the diversity in measurement approaches (reflection, transmission, and resonation), and the extent of microwave techniques (frequency and time domains, continuous wave and UWB pulse, single antenna and antenna array etc.), measurement methods can be flexibly customised to suit the requirements. Studies suggest that many deteriorative biochemical and microbiological processes that take place during the gradual spoilage of food materials have a remarkable influence in the microwave frequency region (Kent et al. 2007). Therefore, microwave has been increasingly used for quality evaluation(Schimmer et al. 2008;Castro-Giráldez et al. 2010a),freshness and storage life (Guo et al. 2010), determination of ingredients (Daschner et al. 2000;Kent et al. 2002), composition analysis(Kent et al. 2001;Daschner and Knöchel 2003), contamination analysis (Shaji and Akhtar 2013), and structure monitoring during aging process (Pacquit et al. 2006;Clerjon and Damez 2007;Jilnai et al. 2016), etc. In the recent years, there are dramatic advances in calibration methods and inexpensive microwave components become commonly available (Trabelsi and Nelson 2016). This offers an opportunity of developing new generation low-cost microwave sensors for particular use scenarios, including on-line quality evaluation in food manufacturing.

In microwave technologies, frequency domain dielectric spectroscopy is one of the most popular methods, and most reported studies are in-lab investigations based on laboratory instruments (Daschner et al. 2000). There are also time domain measurement devices developed for food quality evaluation by determining the dielectric properties (Schimmer et al. 2004; Kwok et al. 1979). Instruments for industrial applications appear and some are the miniaturised handheld devices (Kent 1990). Recent advances in microwave components, smart sensors, and relevant ICT technologies provide new opportunities for the application of microwave sensors in food industry. For example, modern MMIC components 
promise new microwave sensor systems by miniaturising the size, dropping the power consumption, and decreasing the cost. Some commercial UWB components make it possible to extract rich spectrum information by generating a nanosecond pulse for measurement with a single miniature SoC unit (Taylor 2012). In addition, the continuous progress in information technologies has generated new concepts for sensor modules to suit future industry, where flexible data communication and ubiquitous data access are required for collaborative automation and process optimisation towards smart manufacturing.

The technical progress and cost reduction of microwave devices have fostered some innovative applications such as presence detector, indoor positioning (Decawave Ltd, 2017), and respiration monitoring (Novelda, 2017). However, microwave sensor technologies for food evaluation are mostly constrained to in-lab investigations. The lack of on-line solutions for food industryand prosperity of relevant enabling technologies are a cause for concern and indicate a need of research in this area. The objectives of this review are: (1) to give a comprehensive survey of microwave sensor technologies applied for food measurement, (2) to define the technological gap of microwave sensor for on-line applicationsin industry, and (3) to outline the prospect of potential solutions for future food industry with the new emerging technologies. This review will firstly identify the parameters for food quality evaluation within a theoretical background, and then go deeply into the existing measurement methods, technologies, and calibration methods. Finally, the technological gap is determined and the potential solutions are proposed.

The remainder of the paper is structured as follows: Section 2 briefly introduces the food evaluation technologies and the fundamentals of microwave sensor. Sections 3 and 4 classify the methods and technologies of microwave measurement, and the calibration methods with in-depth analysis. Section 5 identifies the challenges and suggests potential solutions. And then, section 6 concludes the work.

\section{Microwave Sensor Technologyfor Food Quality Evaluation}

Before microwave sensor technology, this section starts with the concept of food quality and the parameters used to describe food quality, followed by anbrief comparison to the food quality evaluation technologies.Then,the fundamental theories in microwavemeasurement is introduced.

\section{I Food Quality EvaluationTechnologies}

The term 'food quality' can be described with the frequently cited definition of food quality as "a combination of attributes or characteristics of a product that have significance in determining the degree of acceptability of the product to a user”. These attributes include external factors such as appearance (size, shape, colour, gloss, and consistency), texture, flavour, and internal composition (chemical, physical, microbial) (Tanner 2016).The most important quality related changes are chemical reaction, microbial reaction, biochemical reaction, and physical reaction (Van Boekel, 2008). Quality indicators are not constant and the quality of a food changes over time. Therefore, food quality measurement is essential to food industry including the stages of production, storage, and transport. The fundamentals of food quality sensors are to determine the quality related changes with sensor technologies, mostly focusing the sensing of physical and chemical properties. Example sensor devices for online application of modern industry are as shown in Figure 1. With the sensor technologies, the parameters like food moisture content, metal in meat products, and Near-Infrared (NIR) data of food products can be collected foronline quality evaluation.

There are many sensor technologies can be potentially applied for food evaluation and analysis. The commonly used methods are summarised in Table 1.

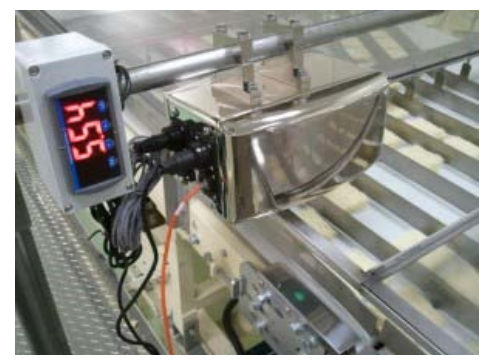

(a) Food moisture sensor (MoistTech Corp., 2017)

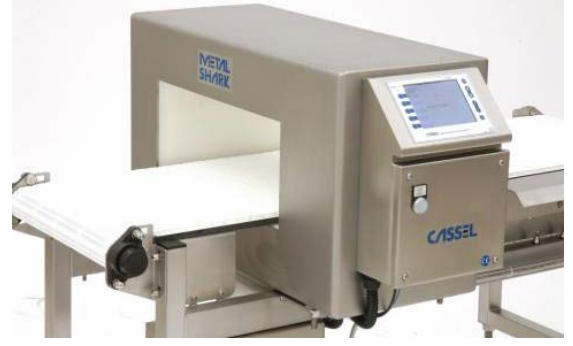

(b) Metal detector for meat products (Cassel Messtechnik, 2017)

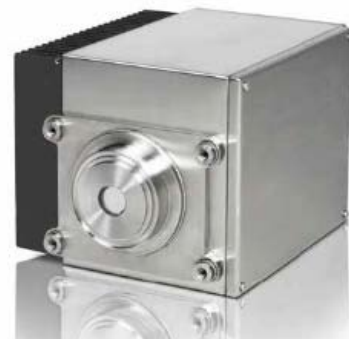

(c) In-line NIR analyser (Perten Instruments, 2017)

Figure I. Food Quality EvaluationSensors

According to Table 1, the food quality evaluation technologies each have their advantages and disadvantages. The distinctive advantage of microwave sensor is its contactless and direct measurement of internal of food with wide frequency range to obtain rich information. Low spatial resolution, hard to calibrate, and no external characteristic 
measurement are the disadvantages. This investigation will give an in-depth overview of the peer investigations taking advantage of the microwave sensor technology for food quality evaluation, and suggest potential solutions to overcome the technical challenges based on some new emerging technologies.

Table I. Food Quality Measurement Technologies

\begin{tabular}{|c|c|c|}
\hline Technologies & Strengths & Weaknesses \\
\hline $\begin{array}{l}\text { Ultrasound spectroscopy } \\
\text { (Khairi et al., 2015) }\end{array}$ & $\begin{array}{l}\text { Contact/contactless, non-destructive, rapid, accurate, } \\
\text { low cost, simple system }\end{array}$ & No spatial information/low spatial resolution \\
\hline $\begin{array}{l}\text { Fibre optical biosensor } \\
\text { (Narsaiah et al., 2012) }\end{array}$ & $\begin{array}{l}\text { Contactless, non-destructive, compact design, high } \\
\text { sensitivity and specificity, remote monitoring }\end{array}$ & $\begin{array}{l}\text { Long response time, no spatial } \\
\text { information/low spatial resolution }\end{array}$ \\
\hline $\begin{array}{l}\text { Near-infrared } \\
\text { spectroscopy(NIRS) (Porep } \\
\text { et al., 2015) }\end{array}$ & $\begin{array}{l}\text { Contactless, non-destructive, both physical and } \\
\text { chemical variations, low cost, environment friendly, } \\
\text { rapid, for on-line application }\end{array}$ & inforn \\
\hline $\begin{array}{l}\text { Computer vision } \\
\text { (Nandhini et al., 2013) }\end{array}$ & $\begin{array}{l}\text { Contactless, non-destructive, both physical and } \\
\text { chemical variations, defect measurement, can be used } \\
\text { for different kinds of food }\end{array}$ & l characteristic \\
\hline $\begin{array}{l}\text { Hyperspectral imaging } \\
\text { (Huang et al., 2014) }\end{array}$ & $\begin{array}{l}\text { Contactless, non-destructive, both physical and } \\
\text { chemical analysis, defect measurement, broad spectral } \\
\text { information, can be used for different kinds of food }\end{array}$ & exity \\
\hline Electric impedance & $\begin{array}{l}\text { Both physical and chemical variations, internal } \\
\text { characteristic measurement }\end{array}$ & 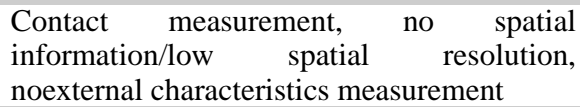 \\
\hline $\begin{array}{l}\text { Radio frequency (RF) and } \\
\text { microwave }\end{array}$ & $\begin{array}{l}\text { Contact/contactless, non-destructive, both physical and } \\
\text { chemical variations, fast, sensitive, direct internal } \\
\text { characteristics measurement, wide frequency } \\
\text { bandwidth }\end{array}$ & $\begin{array}{l}\text { No spatial information/low spatial } \\
\text { resolution, hard to calibrate, noexternal } \\
\text { characteristics measurement }\end{array}$ \\
\hline $\begin{array}{l}\text { Gas sensor array } \\
\text { (Matindoust et al, 2016) }\end{array}$ & $\begin{array}{l}\text { Contactless, non-destructive, low cost, for spoilage, } \\
\text { gas and toxin measurement }\end{array}$ & operty measurement only \\
\hline $\begin{array}{l}\text { pH sensor } \\
\text { (Huang et al.,2012) }\end{array}$ & Simple system, chemical properties measurement & $\begin{array}{l}\text { Contact measurement, local test, chemical } \\
\text { property measurement only }\end{array}$ \\
\hline
\end{tabular}

\subsection{Microwave Sensor Food Evaluation and Analysis}

The internal factors of food products including physical, chemical, and microbial features are very important parameters which are strongly influenced by the properties such as composition and storage time (Schimmer et al. 2004). Food of different compositions differs in dielectric properties including permittivity and conductivity that determine how it reacts to an external electromagnetic field. Since the moisture content and composition of fresh food should be in a reasonable range, the dielectric properties of fresh food should be also in a certain level. Therefore, the spoilage and water evaporation of food can be determined by measuring the change in dielectric properties. In addition, the salt content, ingredients, and contamination affecting the dielectric properties of food materials can be measured and evaluated (Guan et al. 2004). Theories and techniques for determining dielectric properties have been comprehensively discussed in (Haq 2002). The microwave sensor systems are designed to evaluate the quality of food by determining the dielectric properties of food through its influence to the propagation of microwave in the forms reflection, penetration, transmission, scattering and resonation, etc.

\subsection{Fundamentals of MicrowaveSensor Technology}

The fundamentals of microwave sensors are based on the fact that the interaction between microwaves and the medium of propagation is determined by the complex relative permittivity $\varepsilon_{r}$ and relative permeability $\mu_{r}$ of the medium, i.e.

$$
\begin{array}{r}
\varepsilon_{r}=\varepsilon^{\prime}-j \varepsilon^{\prime \prime}(1) \\
\mu_{r}=\mu^{\prime}-j \mu^{\prime \prime}(2)
\end{array}
$$

where $\varepsilon^{\prime}$ signifies the ability to store electric energy and $\varepsilon^{\prime \prime}$, the ability to convert electric energy into heat. $\mu^{\prime}$ and $\mu$ "representrespectively the portion ofmagnetic energy stored and lost in a material. However, since food materials have low influence on magnetic field, the measurements are mainly determined by $\varepsilon^{\prime}$ and $\varepsilon^{\prime \prime}$, which are called dielectric constantand loss factor.

Microwave sensor determines the dielectric properties in propagation of electromagnetic field to reveal the parameters of food objects mainly through three measurement modes, reflection, transmission and resonation.In order to illustrate the transmission of microwave in the measurement, the following model is concentrated on the special case for planar samples in free-space.Figure 2 gives a planar sample with thickness of $d$ placed in free space. It is assumed that 
planer sample is of infinite extent laterally so that diffraction effect at the edge can be neglected. A linearly polarised, uniform plane wave $E_{i}$ is incident normally on the sample, and $E_{r}$ and $E_{t}$ are the reflected and transmitted fields. The scattering parameters $S_{11}$ and $S_{21}$ are measured in free space for the normally incident plane wave(Chen et al. 2004).
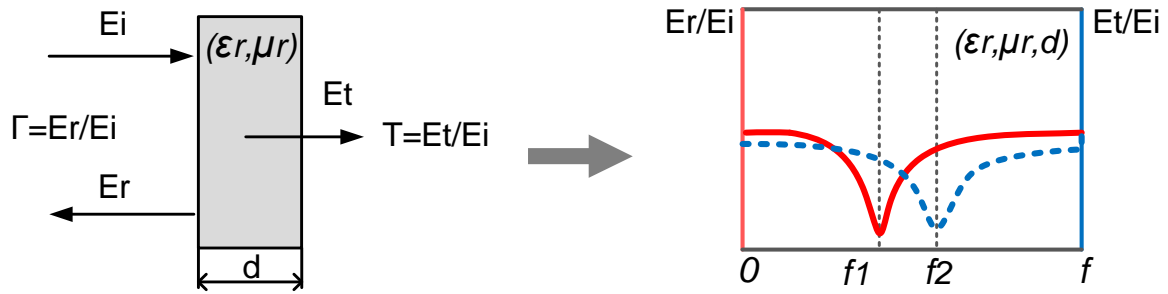

Figure 2. Propagation of Microwave in Planar Sample

By applying boundary conditions at the air-sample interface, it can be shown that the measureablescattering parameters $S_{11}$ and $S_{21}$ are related to reflection coefficient $\Gamma$ and transmission coefficientTby the following equations (Ghodgaonkar et al. 1990):

$$
\begin{gathered}
S_{11}=\Gamma\left(1-T^{2}\right) /\left(1-\Gamma^{2} T^{2}\right)(3) \\
S_{21}=T\left(1-\Gamma^{2}\right) /\left(1-\Gamma^{2} T^{2}\right)(4)
\end{gathered}
$$

From (3) and (4), $\Gamma$ and $T$ can be written as (Weir, 1974):

$$
\begin{gathered}
\Gamma=\chi \pm \sqrt{\chi^{2}-1} \\
T=\left(S_{11}+S_{21}-\Gamma\right) /\left(1-\left(S_{11}+S_{21}\right) \Gamma\right)
\end{gathered}
$$

where

$$
\chi=\left(S_{11}^{2}-S_{21}^{2}+1\right) / 2 S_{11}(7)
$$

The reflection and transmission coefficient $\Gamma$ and Tof the air-sample interface are given by:

$$
\begin{array}{r}
\Gamma=E_{r} / E_{i}=\left(Z_{s n}-1\right) /\left(Z_{s n}+1\right)(8) \\
T=E_{t} / E_{i}=\exp (-\gamma d)(9)
\end{array}
$$

In (8) and (9), $Z_{\mathrm{sn}}$ and $\gamma$ are the normalised characteristic impedance and propagation constant of the sample. They are related to permittivity and permeability by the following equations:

$$
\begin{aligned}
\gamma & =\gamma_{0} \cdot \sqrt{\varepsilon_{r} \mu_{r}}(10) \\
Z_{\text {sn }} & =\sqrt{\mu_{r} / \varepsilon_{r}}(11)
\end{aligned}
$$

where $\gamma_{0}$ is the propagation constant of free space given by $\gamma_{0}=j 2 \pi / \lambda_{0}$ ( $\lambda_{0}$ is the free space wavelength). From (8), (10) and (11), we obtain

$$
\begin{gathered}
\varepsilon_{r}=\left(\gamma / \gamma_{0}\right)(1-\Gamma) /(1+\Gamma) \\
\mu_{r}=\left(\gamma / \gamma_{0}\right)(1+\Gamma) /(1-\Gamma)
\end{gathered}
$$

Since permeability of food materials approximately equals to that of vacuum, the food analysiscanbe based on the variation of $\varepsilon_{r}, \Gamma$, and $T$. The dielectric parameters can be determined by measuring both $S_{11}$ and $S_{21}$.For reflection mode, the variation of $\varepsilon_{r}$ and $\Gamma$ due to qualitychange ofthe food samplecan be determined by the measurement and analysisof $S_{11}$. For transmission mode, the variation of $\varepsilon_{r}$ and $T$ due to quality change ofthe food sample can be determined by measuring $S_{21}$ and the thickness of sample $d$. Different from transmission and reflection, resonation mode determines the dielectric properties by measuring the resonant frequency of a sensor module interacting with the testing materials. Dielectric change in the material results in a shift of resonant frequency. Physical model and theoretical calculation of the measurement depends on the structure of the resonator.

For practical measurements, the propagation model of the electromagnetic wave is more complicated than the planar sample presented above due to the gains of transmitting and receiving antennas, polarisation of antennas, distance of sample between the antennas, size of the samples, anisotropy of sample, ambient reflection, and temperature etc.(Pozar 2005). Therefore, methods to purify the signal and obtain the accurate values with respect to system design, signal conditioningcircuits, and data processing algorithms are crucial to the measurement.

\section{An Overview ofMicrowave Sensorsfor FoodEvaluation and Analysis}

\section{I Microwave Sensors}

It has been reported that microwave propagation is sensitive to the freshness and degradation of food(Guo et al. 2010; Pacquit et al. 2006). The degradationof food finally reflects in a variation of permittivity, which provides the possibility 
to determine the quality with an electromagnetic measurement systems (Venkatesh and Raghavan 2004).The sensor systems are used to obtain electrical data that characterises materials as propagation medium, and these electrical data can be used to calculate the moisture content(Knöchel et al. 2001), contamination(Shaji and Akhtar 2013), freshness(Pacquit et al. 2006), calories(Lexa et al. 2015), and composition of a material(Kent et al. 2001).There aremany valuablefindings thatare regarded as building blocks ofmicrowave sensors for food quality evaluation, and they have already demonstrated the feasibility. A number of investigations on measuring food of different categories with microwave sensor technologies have been reported in the recent years, such as corn (Seifi and Alimardani 2010), mashed potato (Guan et al. 2004), meat(Clerjon and Damez 2009), chicken(Zhuang et al. 2007), beef(Ng et al. 2009), fish(Kent et al. 2007),prawn, poultry meat and scallops(Kent and Anderson 1996), butter(Shiinokiet al. 1998), yoghurt(Bohigaset al. 2008), milk (Agranovich et al. 2015), fruit juice(Lee et al. 2010), vegetable oil(Korostynska et al. 2013),cereal grain and seed(Trabelsi and Nelson 2003), etc.General principles, technologies, and somemicrowave sensor based food measurement applicationshave been discussed in several review articles(Nelson 2006; Gibson et al. 2008; Jha et al. 2011; Chandrasekaranet al.2013).

In brief, the past investigations reveal that: (1) Microwave sensor as a non-destructive method has been widely investigated for measurement of agricultural and foodstuffs. But most of the investigations are for proof-of-concept studies, which are not ready for food industry.(2) Since materials differ in frequency responses, wide frequency bandwidth of microwaves provides more chances to determine particular variables. (3) Since microwave measurementisa combination result of multiple variables including composition, size, temperature, and frequency employed, calibration is critical to the accuracy of measurement.

Among the studies, most investigations are based on the determination ofdielectric properties using laboratory instruments, such as Vector Network Analyser (VNA) and impedance analyser. There are fewstudies on instrumentsfor in-situ and on-line measurement. Investigations on UWB pulse based microwave sensor are reported in heuristic studies, and time domain measurement is proved a promising solution.

\subsection{Methods and Techniques}

Microwave sensor for food measurement is not a new emerging topic. Investigations in the early stage employ scientific instruments such as VNA and impedance analyser to determine dielectric properties of food. Due to the high cost and bulky size of microwave components, it is difficult to find custom-designed microwave sensor systems. Until recently, some custom-designed microwave sensorsare reported in the literature. In principle, microwave measurements can be classified into frequency domain andtime domain measurements. Frequency domain methods measure the transmission or reflection coefficient to determine the complex permittivity. Time domain methods record the timedomain waveform, and then compare with the waveform before measurement or apply the Fourier-Transform and proceed in the frequency domain.According to the front-end sensorsapplied, microwave sensors can be categories intolab-instrument based sensors and custom-designed sensors.This section illustrates the microwave sensor systemsfocusing on the measurement methods and sensor technologies.

\subsection{Frequency Domain Dielectric Spectroscopy}

Since frequency domain measurement can be carried out withlab-instruments such as open-ended coaxial line with a VNA, and it takes advantage of the wide frequency range of microwave, a great amount of investigations have been performed with dielectric spectroscopy for food measurement. With frequency domain spectroscopy, the frequency dependent permittivity $\varepsilon_{r}(f)$ of food materialscanbedetermined with S-parameters using microwave instruments in combination with suitable sensors. Someinvestigations employing the microwave dielectric spectroscopy for food measurement are given in Table 2.

According to Table 2, frequency domain spectroscopy has beenwidely applied for food measurements of different categories, including fish, meat, grain, oil, yoghurt, vegetables, etc. Some commonly used lab-instruments, such as openended coaxial probe, horn antenna, waveguide, and cavity resonator are used with a VNA to set up the measurement systems, and frequencies used are between 1-20GHz. The reported investigations have demonstrated the feasibility of dielectric spectroscopy for food measurement. Although fundamentals are identical, the studies are conducted for different purposes, which are summarized as follows.

(1) Food composition analysis

Dielectric spectroscopy can be used to determine specific ingredients or the composition of food, such as determining added water (Kent et al. 2002), food composition analysis (Kent et al. 2001), predicting food composition (Daschner et al. 2000), and food chemical analysis (Bjarnadottir et al. 2015). It is also used to model the dielectric behaviour of food regarding variation of composition, such as modeling of dielectric behaviour of sugar content in yoghurt (Bohigas, Amigó and Tejada, 2008). By composition and dielectric behaviour analysis, the variation of food can be determined for further evaluation in food production or storage procedures. 
Table 2. Applications of Microwave Spectroscopy Measurement

\begin{tabular}{|c|c|c|c|c|}
\hline Food Samples & $\begin{array}{c}\text { Purpose of } \\
\text { Measurement }\end{array}$ & Sensor module & Hardware & $\begin{array}{l}\text { Frequency } \\
\text { Used }\end{array}$ \\
\hline Pork (Kent et al. 2002) & $\begin{array}{l}\text { Determining added water } \\
\text { in pork }\end{array}$ & Open-ended coaxial probe & $\begin{array}{l}\text { Computer } \\
\text { VNA }\end{array}$ & $0.13-18 \mathrm{GHz}$ \\
\hline $\begin{array}{l}\text { Yoghurt (Bohigas et al. } \\
\text { 2008) }\end{array}$ & $\begin{array}{l}\text { Determining sugar in } \\
\text { yoghurt }\end{array}$ & $\begin{array}{l}\text { Coaxial probe Agilent } \\
\text { 85070C }\end{array}$ & HP8510C and 8517B & $1-20 \mathrm{GHz}$ \\
\hline $\begin{array}{l}\text { Prawns, pork, chicken, and } \\
\text { fish (Kent et al. 2001) }\end{array}$ & Composition analysis & $\begin{array}{l}3.0 \mathrm{~mm} \text { Open-ended } \\
\text { coaxial sensor }\end{array}$ & $\begin{array}{l}\text { Automatic } \\
\text { analyser }\end{array}$ & $0.2-12 \mathrm{GHz}$ \\
\hline Meat (Daschner et al. 2000) & $\begin{array}{l}\text { Determination of water in } \\
\text { foods }\end{array}$ & $\begin{array}{l}\text { 3.0mm open-ended } \\
\text { coaxial line }\end{array}$ & HP8510 & $0.2-12 \mathrm{GHz}$ \\
\hline $\begin{array}{l}\text { Ham (Bjarnadottir et al. } \\
\text { 2015) }\end{array}$ & $\begin{array}{l}\text { Determination of water } \\
\text { activity, salt content and } \\
\text { water content }\end{array}$ & $\begin{array}{l}\text { Rectangular } \\
\text { resonator }\end{array}$ & VNA & $2-6 \mathrm{GHz}$ \\
\hline $\begin{array}{l}\text { Pork meat (Castro-Giráldez } \\
\text { et al. 2010) }\end{array}$ & Quality detection & $\begin{array}{l}\text { Coaxial probe Agilent } \\
85070 \mathrm{E}\end{array}$ & Agilent E8362B & $0.5-10 \mathrm{GHz}$ \\
\hline $\begin{array}{l}\text { Mixture of oil, sugar, water } \\
\text { (Lexa et al. 2015) }\end{array}$ & Estimate calorie of food & Spiral antenna PSA 218R & Agilent E5071C & $0.9-8.5 \mathrm{GHz}$ \\
\hline $\begin{array}{l}\text { Cereal grain, oilseed } \\
\text { (Trabelsi and Nelson 2003) }\end{array}$ & $\begin{array}{l}\text { Measurement of dielectric } \\
\text { properties }\end{array}$ & $\begin{array}{l}\text { Horn antennas model } \\
\text { AHO-2077-N }\end{array}$ & VNA & $5-17 \mathrm{GHz}$ \\
\hline Wheat (Bartley et al. 1998) & $\begin{array}{l}\text { Measuring moisture } \\
\text { content wheat }\end{array}$ & Horn antennas & VNA & $10-18 \mathrm{GHz}$ \\
\hline $\begin{array}{l}\text { Winter wheat (Nelson and } \\
\text { Stetson 1976) }\end{array}$ & $\begin{array}{l}\text { Determination } \\
\text { dielectric properties }\end{array}$ & $\begin{array}{l}\text { Coaxial sample holder, } \\
\text { waveguide, etc. }\end{array}$ & $\begin{array}{l}\text { General radio impedance } \\
\text { bridge, VSWR indicator, } \\
\text { etc. }\end{array}$ & $\begin{array}{l}250 \mathrm{~Hz} \\
12.1 \mathrm{GHz}\end{array}$ \\
\hline $\begin{array}{l}\text { Fish products (Kent et al. } \\
\text { 2000) }\end{array}$ & $\begin{array}{l}\text { Determination of prior } \\
\text { treatment }\end{array}$ & Open-ended coaxial probe & VNA & $0.4-6.2 \mathrm{GHz}$ \\
\hline $\begin{array}{l}\text { Chicken, Scallops (Kent and } \\
\text { Anderson 1996) }\end{array}$ & $\begin{array}{l}\text { Determination of added } \\
\text { water }\end{array}$ & $\begin{array}{l}3.5 \mathrm{~mm} \text { coaxial probe } \\
\text { HP85070A }\end{array}$ & HP8719A & $0.2-12 \mathrm{GHz}$ \\
\hline Beef(Ng et al. 2009) & $\begin{array}{l}\text { Determination of fat and } \\
\text { salt content }\end{array}$ & $\begin{array}{l}\text { Open-ended coaxial probe } \\
85070 \text { E, waveguide WG- } \\
284 \text { and WR-90 }\end{array}$ & НР8510В & $1-40 \mathrm{GHz}$ \\
\hline $\begin{array}{l}\text { Mashed potato (Guan et al. } \\
\text { 2004) }\end{array}$ & $\begin{array}{l}\text { Dielectric properties in } \\
\text { microwave } \\
\text { processing }\end{array}$ & $\begin{array}{l}\text { Open-ended coaxial-line } \\
\text { probe }\end{array}$ & $\begin{array}{ll}\text { Agilent } \quad 4291 B & R F \\
\text { Impedance Analyser } & \end{array}$ & $1 \mathrm{M}-1.8 \mathrm{GHz}$ \\
\hline $\begin{array}{l}\text { Uncooked chicken breast } \\
\text { (Zhuang et al. 2007) }\end{array}$ & Quality measurement & Open-ended coaxial probe & Impedance analyser & 0.01-1.8Ghz \\
\hline $\begin{array}{l}\text { Chicken meat (Trabelsi } \\
\text { 2013) }\end{array}$ & $\begin{array}{l}\text { Effects of aging on } \\
\text { dielectric properties }\end{array}$ & Open-ended coaxial probe & Agilent PNA-L N5230C & $0.2-20 \mathrm{GHz}$ \\
\hline
\end{tabular}

(2) Determination of food characteristics or parameters

Dielectric spectroscopy is also used for analysis of food characteristics and parameters, such as quality defects, calories, density, storage, etc. Applications include the determination of quality defects in porcine muscle (CastroGiráldez et al. 2010c), calories of homogeneous mixtures of oil, sugar, and water (Lexa et al. 2015), bulk density and moisture content of cereal grain and oilseed (Trabelsi and Nelson 2003), moisture content of wheat (Bartley et al. 1998), the dielectric properties of hard red winter wheat (Nelson and Stetson 1976). In these studies, dielectric spectroscopy is used to obtain the characteristics and parameters of foodstuffs with data analysis.

(3) Distinguishing food treatment in production

Dielectric spectroscopy can also be used to distinguish treatment of food in production. Kent et al. (2000) applied microwave dielectric spectra to determine the prior treatment of fish and fish products, such as prawn, cod, haddock, and saithe. Kent and Anderson (1996) measured the dielectric spectra of chicken and scallop to distinguish treatments of the samples. By measuring the dielectric spectroscopy, the variation of food in composition during the treatments can be determined, and the treatment can be distinguished.

(4) Discovering new features of food

Another application of dielectric spectroscopy is to discover features of food. $\mathrm{Ng}$ et al. (2009) found the optimum frequency for determiningfat in beef was between $8-12 \mathrm{GHz}$ and that for salt was below 4GHz. Guan et al. (2004) measured the dielectric properties of mashed potatoes relevant to microwave and RF pasteurization and sterilization processes, and investigated relationship between dielectric properties with moisture content, temperature, and salt content. Trabelsi(2013) found dielectric constant of chicken meat decreased with storage duration at all frequencies while dielectric loss factor increased with storage duration below $4 \mathrm{GHz}$ and remained constant at frequencies above that. These new discovered features can be applied for food quality evaluation in production and storage. 
Admittedly, dielectric spectroscopy is an effective and widely used approach, which is helpful to food quality evaluation, food manufacturing and storage. It takes advantage of the wide frequency range of microwave to determine the characteristics of materials.It is an effective method to build the response pattern of food sample to the wide microwave frequencyrange, which is promising for scientific research and industrial applications.

\subsubsection{Time Domain Measurement}

Time domain measurement is a technique to determine the characteristics of samples by observing reflected or transmitted waveforms called Time Domain Reflectometry (TDR) or Time Domain Transmissometry (TDT). It is considered to be independent of mass per area of test sample and does not suffer from measurement ambiguities, which are common to frequency domain measurement. TDR originally is based on measuring the travelling time of electromagnetic pulses along an electrical line, which is related to the frequency domain via the inverse FourierTransform. Of particular interest in time domain measurement is the application of UWB technology, which transmits and receives pulse based waveforms compressed in time domain. Time domain UWB measurement isusually achieved by launching a shortpulse into a low-loss coaxial transmission line containing a section with the measurement sample, and receiving the reflected or transmitted pulse for analysis.

Different from the frequency spectroscopy, the setup of time domain measurement are mostly custom-designed with low-cost commercial components.Examples are listed in Table 3.

Table 3. Investigations with Time Domain Measurement

\begin{tabular}{|c|c|c|c|c|}
\hline Food Samples & $\begin{array}{c}\text { Purpose of } \\
\text { Measurement }\end{array}$ & Sensor module & Hardware & Frequency \\
\hline $\begin{array}{l}\text { Granular } \quad \text { agricultural } \\
\text { products (Kwok, Nelson and } \\
\text { Bahar 1979) }\end{array}$ & $\begin{array}{l}\text { Dielectric } \\
\text { properties }\end{array}$ & $\begin{array}{l}\text { Coaxial line, coupling } \\
\text { nut, and sample holder }\end{array}$ & TDR (HP1415A) & $30 \mathrm{M}-2 \mathrm{GHz}$ \\
\hline $\begin{array}{l}\text { Honey water (Puranik et al., } \\
\text { 1991) }\end{array}$ & $\begin{array}{l}\text { Dielectric } \\
\text { properties }\end{array}$ & S-6 sampling head & $\begin{array}{l}\text { 7S12 TDR unit, } \\
\text { S-52 Pulse generator, } \\
\text { Tektronix } 7854 \text { oscilloscope }\end{array}$ & $\begin{array}{l}25 \mathrm{ps} \text { pulse at } \\
1 \mathrm{KHz}\end{array}$ \\
\hline Frozen fish (Kent 1975) & $\begin{array}{l}\text { Dielectric } \\
\text { properties }\end{array}$ & Sample cell with slab line & Sampling oscilloscope & $10 \mathrm{GHz}$ \\
\hline $\begin{array}{l}\text { Chilled fish (Schimmer et } \\
\text { al. 2004;Schimmer et al. } \\
\text { 2008) }\end{array}$ & $\begin{array}{l}\text { Quality and } \\
\text { storage time }\end{array}$ & Open-ended coaxial probe & Custom-designed circuits & $\begin{array}{l}100 \mathrm{ps} \text { pulse at } \\
5 \mathrm{MHz}\end{array}$ \\
\hline $\begin{array}{l}\text { Bulk food material } \\
\text { (Schimmer et al. 2005) }\end{array}$ & Food quality & $\begin{array}{l}\text { Double-ridged } \\
\text { antennas }\end{array}$ & $\begin{array}{l}\text { Sampling oscilloscope TDS- } \\
8000\end{array}$ & $\begin{array}{l}400 \mathrm{ps} \text { pulse at } \\
0.2 \mathrm{MHz}\end{array}$ \\
\hline
\end{tabular}

Some TDR investigations use separate modules to demonstrate the feasibility. Kwok et al. (1979)pointed out the disadvantages of frequency domain measurement for agriculture materials and attempted to overcome them with time domain spectroscopy.The study of low frequency single-reflection and 30MHz-1.7GHz multiple-reflection demonstrated the feasibility of determining frequency dependence of dielectric properties with TDR. A TDR unit and an oscilloscope are applied to investigation the dielectric properties of honey-water mixture, and results demonstrate that the dielectric spectrum of pure honey could be described with Davidson-Cole model, and adding water to honey leaded to broadening of the spectrum(Puranik et al. 1991). Kent (1975) measured the dielectric properties of frozen fish with time domain spectroscopy, which employed the complete reflected pulse from a sample terminated in a 50Ohm load. The measurement of various parameters is sufficiently accurate to permit this method to investigate frozen biological materials slike fish flesh.

Sometimes, measurement setup becomes the focus of some investigations. A microwave TDR instrument applying a pulse response for determining food quality is described bySchimmer et al.(2004, 2008). The frequency bandwidth is from DC to $5 \mathrm{GHz}$, the pulse step rise-time is $100 \mathrm{ps}$, and the sample rate is $100 \mathrm{GHz}$. The pulse and step generator are set up with commercially available MMICs, such as frequency dividers and UWB amplifiers. The data isdirectly processed by applying multivariate statistics of principal components analysis (PCA). Different fromTDR, a TDT method for determination of moisture content of bulk food materials using a sub-nanosecond UWB pulse is described by Schimmer et al. (2005). The received signal is analysed with different data processing methods, such as direct analysis, multiple linear regression, PCA, and Artificial Neural Networks (ANN).

UWB pulse-based time domain measurements have many advantages over traditional methods which make it more suitable for some applications. They have potentially low complexity, low-cost,high spatial resolution, and more importantly good time domain resolution. In addition, they do not suffer from measurement ambiguity and may even be realised with a lower hardware effort. The attributes of low-power consumption, negligible interference to narrowband 
systems, inherent immunity against detection and interception, and strong penetration ability etc. make it a good candidate for food measurement. Therefore, UWB pulse based measurement is recognised as a promising solution.

\subsection{Microwave Measurement Systems}

Microwave measurement systems are constructed with front-end sensors unit and processing devices in different ways. Many traditional microwave methods for permittivity characterization areapplied to food measurement. The commonlyused methods are: open-ended coaxial probe reflection measurement, waveguide cell transmission measurement, horn antenna free-space measurement, and resonator cavity measurement, etc.(Gibson et al. 2008)The system setup of microwave measurement systems are given in Figure 3.

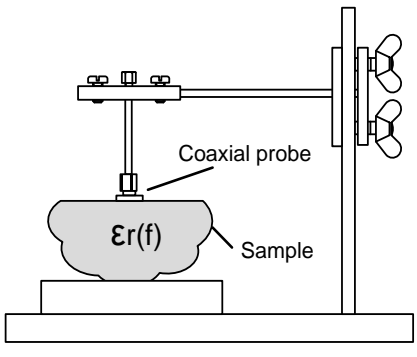

(a) Open-ended Coaxial Line Probe Measurement

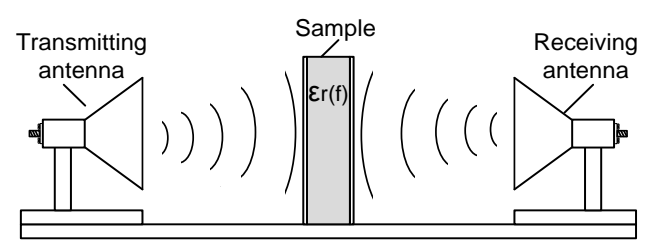

(c) Free-space Measurement

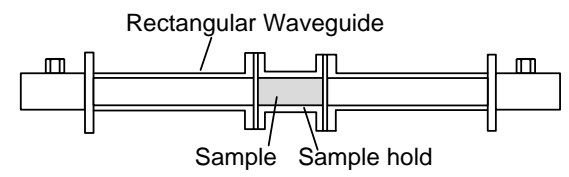

(b) Waveguide Transmission Measurement

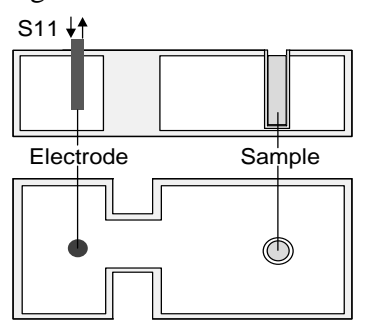

(d) Cavity Resonator Measurements (Kim et al. 2012)

Figure 3. Microwave Measurement Systems

(1) The open-ended coaxial probe method, as shown in Figure 3(a), provides a very convenient method to evaluate dielectric permittivity of liquid and semi-solid. This method is easy to implement and it is therefore widely used, such as determining viscosity and dielectric properties of starch slurries(Bircan and Barringer 1998), on-line salting process in meat industry (Castro-Giráldezet al. 2010b), meat aging and quality defect in porcine muscle (CastroGiráldez et al. 2010c), changes in muscle structure during ageing of bovine meat (Clerjon and Damez 2009).

(2) Waveguide cell transmission measurement, as shown in Figure 3(b), can be used to measure dielectric properties in different ways, such as transmission method, resonant cavity method, open-ended waveguide line, and free space method. These techniques are generally preferred at frequency at about $2.45 \mathrm{GHz}$ to $30 \mathrm{GHz}$. Waveguide sensor was used to determine fat and salt in beef ( $\mathrm{Ng}$ et al. 2009), monitor changes in muscle structure during the ageing of bovine meat and quality loss due to fish freezing (Clerjon and Damez 2007), and measure concentration of liquid compounds(Gennarelli et al. 2013).

(3) Free-space measurement as illustrated in Figure 3(c) is used to obtain the transmission coefficients, and is generally employed at high frequency (about $10 \mathrm{GHz}$ and above). Accurate measurement of the permittivity over a wide range of frequencies can be achieved by free-space techniques. Free-space transmission technique was applied to determine moisture content of wheat (Bartley et al. 1998) and moisture of organic bulk materials (Hinz et al. 1996).

(4) Resonantor technique as illustrated in Figure 3(d) offers the potential of characterising the properties of food material with high accuracy, which determines the dielectric properties of material by measuring the shift of resonant frequency and the change of Q factor of the cavity. Resonant cavity measurement was used for rapid determination of moisture in food (Knöchel et al. 2001) and for real-time measurement of glycemia in pig blood (Kim et al. 2012), etc.

Most measurement systems based on the above methods are setup by combining lab-instruments such as open-ended coaxial probe and waveguide with a processing unit like VNA, and results are obtained by measuring and analysing the S-parameters. These methods are convenient for academic study, but it is bulky, slow, and expensive for on-line measurement in industry. 


\subsection{Custom-designed Microwave Sensor Modules}

In addition to lab-instruments based systems, there are also sensor modules designed for particular cases of measurement. Since sensitivity and frequency characteristics of front-end sensor modules can directly affect the performance of microwave sensors, these devices play an important role in the measurement. Various specialised sensors can be designed to fit particular food measurementscenarios, including microstrip patch antenna, stripline sensor, microstrip resonator, open resonator, ring resonator,Interdigitated Electrode (IDE), coplanar sensor, and Radio Frequency Identification (RFID) sensor, as shown in Figure 4.

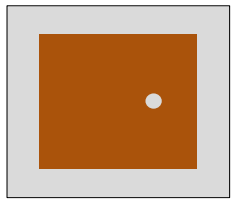

(a) Microstrip patch (Cheng et al. 2014)

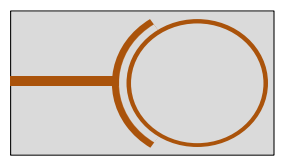

(e) Ring resonator (Jilnai et al. 2016)

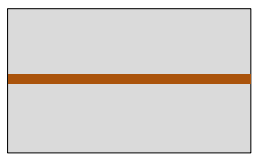

(b) Stripline sensor (Kent 1990)

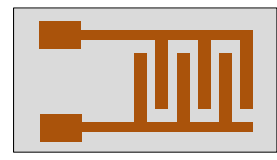

(f) IDE (Korostynska et al. 2013)

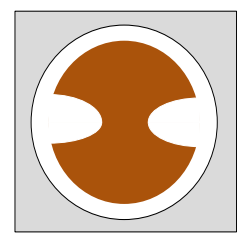

(c) Microstrip resonator (Jackson and Jayanthy 2010)

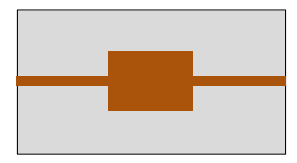

(g) Coplanar sensor (Shaji and Akhtar 2013)

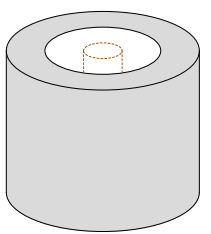

(d) Open resonator (Knöchel et al. 2001)

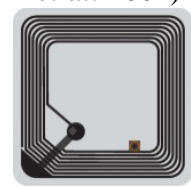

(h) RFID tag (Potyrailo et al. 2012;Fiddes et al. 2014)

Figure 4. Layout of Custom-designed Sensor Modules

The principle of these sensors is to modify the propagation characteristics of microwaveand their interaction with measurement objects in transmission, reflection, or resonation. RFID sensor is an innovative measurement method using the low-cost passive UHF RFID tags as a sensor to detect food parameters. The measurement based on passive RFID sensing approach combines advantages of contactless, battery-free, cost-effective, and offers response selectivity as well.It is found that most of the custom designed sensors are simple in structure, easy to fabricate, low-cost, and low power, which are suitable for cost-effective, portable, on-the-spot measurement.Since they are designed for particular cases of measurement, theysuit the measurement situations well and are usually ready for on-the-spot measurement.

\subsection{Microwave Sensor Solutions for On-line Measurement}

From the above discussion, most microwave sensor solutions based on lab-instruments are for in-lab investigations. There are also measurement systems having the potentials for on-line measurement in food industry. For example, an insitu system for oil palm fruit permittivity and moisture content measurement(Lee et al. 2010), a continuously operating microwave moisture sensor for organic bulk materials (Hinz et al. 1996), a microwave transmission technique to monitor the moisture and salt contents in a butter-making process (Shiinoki et al. 1998), and a microwave coplanar sensor for online composition and moisture content determination(Austin et al. 2014). The free-space transmission method for wheat moisture content determination also has the potential for on-line and non-destructive measurement (Bartley et al. 1998). In addition, an IDE electrode approach that allows real-time identification of the vegetable oil types is reported byKorostynska et al.(2013), which exploits low-power microwave sensing principle and provides cost-effective, portable, on-the-spot measurement.

The high-performance and powerful functions of VNA makes the measurement accurate and multifunctional, but the bulky size and high cost make these solutions inappropriate for industrial applications. Therefore, miniaturised measurement systems for on-line measurement regarding performance, size, and cost are required.

\section{Calibration and Decision-Making}

Microwave sensor measurement usually involves decision-makingwhich can be interpreted as a yes/no problem or a grading process. Since microwave sensor is susceptible to some environmental variations, such as ambient electromagnetic radiation, temperature, and the attributes of food materials, calibration is a critical step to produce reliable and accurate measurement results.Normally, dielectric permittivity $\left(\varepsilon^{\prime}\right)$ of a material varies with the temperature (Karisma et al., 2017), and the food materials are normally temperature dependent dielectric media (Zhong et al., 2016). Therefore, temperature is an important influencing parameter in calibration.It is widely accepted thatbetter calibration can result in better performance of the instruments(Kent 1990).The commonly used 
calibration methods arephysical model based calibration, PCA and Principal Components Regression (PCR), and ANN.

\section{I Physical model based calibration}

The calibration can be done with a particular data model built with a set of experimental data and mathematical equations. The sensor system can provide the measurement value throughcompensation of the raw data with the data model. The strengths of this method of calibration are easy to understand and low complexity. Multi-temperature calibration, mixture equation calibration, and empirical equation calibration are typical physical model based calibration methods.

The multi-temperature calibration method is proposedtoprevent accuracy compromise due to temperature variation in measuring food dielectric over a wide temperature range(Chen et al. 2015). The system was calibrated at $1^{\circ} \mathrm{C}, 25^{\circ} \mathrm{C}, 40^{\circ} \mathrm{C}$, $55^{\circ} \mathrm{C}, 70^{\circ} \mathrm{C}$, and $85^{\circ} \mathrm{C}$, and these calibrations were used to measure the dielectric properties of deionized water around each calibration temperature. The relative errors $(R E)$ of the measured dielectric properties are calculated:

$$
R E=\left(x_{0}-x\right) / x \cdot 100 \%
$$

where $x_{0}$ is the measured dielectric constant or dielectric loss factor, and $x$ is the reported dielectric constant or dielectric loss factor.Results demonstrate that this multi-temperature calibration is helpful for reducing errors and improving accuracy of the temperature dependent dielectric properties measurement, especially low-loss materials.

TheLandau-Lifshitz-Looyenga'sdielectric mixture equation (Trabelsi and Nelson 2003)is applied to provide permittivity data over a wide frequency range at different moisture levels by converting permittivity values of different density to a particular one, e.g. medium bulk density. The calculation is

$$
\varepsilon_{2}=\left[\left(\varepsilon_{1}^{1 / 3}-1\right) \rho_{2} / \rho_{1}+1\right]^{3}
$$

where $\rho_{1}$ is the original bulk density and $\rho_{2}$ is the medium density for a particular moisture content. By measuring the permittivity components, dielectric constant and loss factor of wheat, shelled corn, and soybeans at specific moisture content and bulk densities from $5-17 \mathrm{GHz}$, the equation is applied to adjust the permittivity values to a medium density value for the range of moisture contents of practical interest at $10 \mathrm{GHz}$ and at the same temperature.

An empirical equation is developed to estimate the loss factor of whole-grain wheat from bulk density and moisture content by preparing samples of various densities and measuring dielectric properties of the samples(Sokhansanj and Nelson 1988). The moisture content is expressed as a function of $x$, which in turn is a function of dielectric constant and bulk density at a given frequency:

where $\mathrm{M}$ is the moisture content in percentage, and $x$ is defined as:

$$
M=B_{1}+B_{2} x+B_{3} x^{2}
$$

$$
x=\left(\varepsilon^{1 / 3}-1\right) / \rho
$$

The coefficients B1, B2, and B3 above are estimated using experimental data. Results show that both linear and second-degree polynomial forms showed high correlation coefficients, and polynomial fit had smaller standard errors. The equation covers a frequency range of $1-2.45 \mathrm{GHz}$ and is considered tobesufficiently accurate to estimate the dielectric constant. Loss factors can be estimated in the same way using a second-degree polynomial function of moisture density defined as the result of moisture contentand bulk density.

\subsection{PCA/R}

PCA/R was first introduced for the analysis of dielectric data by Kent and Anderson in 1996 (Schimmer et al. 2004). PCA applies a linear transformation to a set of correlated variables to produce a new set of uncorrelated, standardised and orthogonal variables called components (Kent and Anderson 1996).These components are a linear combination of the original measurable variables, such as the spectral values. Normally, the first few principal components account for a large proportion of the total variance of the original set of variables. If this is the case, the first few principal components can be used to represent the original data as inputs for further analysis. PCR uses PCA to reduce a large, highly correlated set of variables down to a manageable set so that a regression can be performed. The dependent variables are described as principal components that can be regressed on a small number of items, and calibration equation can be constructed after establishing a regression equation.

Each PC explains a fraction of the variance of the data:

$$
Y_{j}=a_{1 j} \cdot X_{1}+a_{2 j} \cdot X_{2}+\ldots+a_{i j} \cdot X_{i}+\ldots+a_{p j} \cdot X_{p}
$$


where $Y_{j}$ is the $j^{\text {th }}$ PC, the $X_{i}$ are the mean centred and standardised original variables $\left(T, \varepsilon^{\prime}\left(f_{i}\right), \varepsilon^{\prime \prime}\left(f_{i}\right)\right)$ of length p and the coefficients in the eigenvector $a_{i j}$ are constants referred to as 'loadings'. The loadings are calculated in sequence by maximising the variance of each PC.

PCA/R is a commonly used calibration method for multi-variable measurement like microwave foodstuffs measurement. Schimmer et al. (2004)applied PCA to derive PCs from time domain spectrometer to establish a PCR formula for the prediction of required material properties, which is applied to the measurement of quality and storage time of chilled fish samples. With the PCA/R, Daschner et al. (2000) collected the dielectric spectra of several kinds of meat and use the data to predict the composition of the materials. Kent et al. (2000) applied PCA to construct a discrimination function to determine the prior treatment of fish and fish products. In general, the PCA calibration is considered a suitable method for the case of extracting information from dielectric measurement.

\subsection{ANN}

ANNis introduced to deal with the complexitynature of the interaction between applied electromagnetic field and test materials.ANN is a method strong in dealing with non-linear relationship of microwave measurement, which is a joint result of several parameters including moisture content, bulk density, frequency, temperature, etc. It is challenging because the sensor output is influenced by the factors in different ways. To deal with this situation, ANN is applied to provide mathematical structures that can be trained to map a set of inputs to a set of outputs.

ANN is applied for composition analysis and for wheat moisture content measurement (Bartley et al. 1998). As inputs, each transmission coefficient contains two parts - amplitude and phase. There is one hidden layer, and the number of neurons associated with this hidden layer is determined by training the network. Multi-layer Feed Forward (MLFF) networks are implemented as a multivariable calibration method for microwave dielectric spectra composition analysis, which is suitable for function approximation(Daschner and Knöchel 2003).Radial Basis Function neural network (RBFANN) is used for non-contact determination of moisture content in bulk materials(Schimmer et al. 2005). Linear regression, PCA, and RBF-ANNare compared and results demonstrate PCA together with RBF-ANN yield the estimations with the lowest error of prediction.In addition, ANN is appliedto determine chemical composition and moisture content of particulate blends on-line with four hidden nodes to investigate whether use of a non-linear module could significantlyincrease accuracy of the model (Austin et al. 2014).

In summary, the ANN is suitable for non-linear data processing, while it suffers from high computational efforts with respect to training process. However, many applications can produce better results than physical model calibration and PCA calibration. The effective integration of different calibration methods may produce a better performance.

\section{The Limitations and Potential Techniques}

Based on the peer investigations illustrated above, this section determines the underlying limitations of microwave sensor technologies, and then envisages the corresponding emerging technologies that can provide potential solutions to deal with the technical challenges.

\section{I Technological Gap}

Generally, the following facts have limited the application of microwave sensors, which can be considered as the major technological gap of microwave sensor technology for on-line application in food industry.

(1) System complexity - Most measurement systems are based on bulky and expensive lab-instruments, which are not suitable for on-line applications in foodindustry. Therefore, customised designs dedicated to food quality evaluation considering the flexibility for industry use are expected. To achieve this target, the microwave sensor systems should be setup with low-cost and miniaturised components with customised designs.

(2) Hard to calibrate - Since microwave circuits are vulnerable to temperature and electromagnetic interference, and measurement frequency, the size, shape, and category of samples all contributes the measurement results, microwave measurements depend largely on the measuring system and the validity of the model used for calibration. This complicate the calibration of microwave measurement.

(3) Low spatial resolution - Microwave sensor is subject to relatively low spatial resolution due to the size of antennas related to the frequency used. Normally, measured intensity represents the average value of an area which limits the resolution of measurement. Using high frequency can reduce the size of antenna, while this will reduce the penetration depth significantly. To balance the resolution and penetration depth, frequency range from hundreds $\mathrm{MHz}$ to several $\mathrm{GHz}$ is generally adopted. 
(4) High-cost of microwave systems - The testing equipment for microwave sensor development such as VNA and spectrum analyser are expensive. High frequency microwave components are usually more expensive than low frequency components. In addition, the cables and circuits usually need shielding which also raises the cost.

The above constraints have raised challenges to on-line measurement in food industry. Evidently, the application of MMICs can potentially simplify the complexity and drop the cost of microwave sensor systems. Some emerging innovative technologies are also promising to deal with the limitations and bridge the technological gap.

\subsection{PotentialSolutions}

This section summarises the potential technologies for food quality evaluation and composition analysis, includingantenna array technology, UWB pulse radar, and Gain-phase detection. Antenna array technology is usually implemented for dielectric imagingwithcorresponding signal processing algorithms, which is commonly used in biomedical, but seldom applied in food measurement. UWB pulse radar time domain measurement is a rapidly progressing techniquewhich is a promising solution for food analysis. Gain-phase detection method normally employs a particular suitable frequency and then detects the gain loss and phase shift after interaction with measured samples, which can largely reduce the complexity and cost.

\subsection{Antenna Array Technology}

An antenna array, physically or synthetically formed, can be used for reconstructing dielectric images, which has enriched the special area of microwave sensors measurement and enabled possibilities of dielectric construction of the object under test. The antenna array based microwave sensor can be used for both reflection and transmission mode measurement.The commonly used designs are linear array(Weiet al. 2013), circular array(Alkhalifeh et al. 2012), and planar array(Zhuge and Yarovoy 2012), which are shown in Figure 5(a), 5(b), and 5(c).

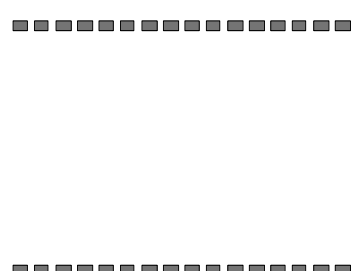

(a) Linear Array

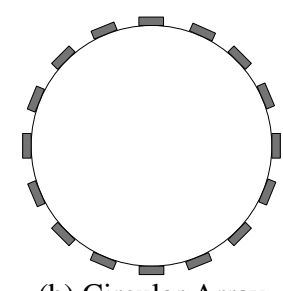

(b) Circular Array

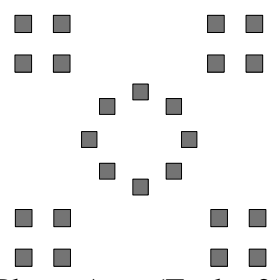

(c) Planar Array(Taylor 2012)

Figure 5. Antenna Arrays for Microwave Sensor Measurement

With an antenna array, the 2D images of objects can be generated and the analysis of dielectric properties can be conducted. An example of moving tomatoes measured with a continuous wavelinear array scanning is given in Figure 6 (Menget al. 2016), where horizontal and vertical axes denote the spatial location, and the colour code denotes the attenuation coefficient. Withanappropriate scanning and a data processing methods, the spatial resolution can be improved.
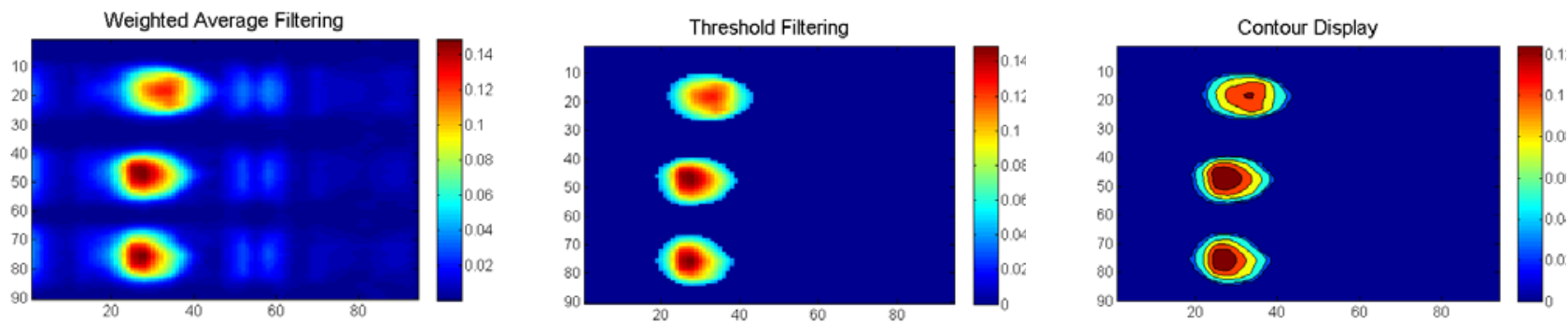

Figure 6. 2D Imaging of Moving Tomatoes with Linear Array Scanning

The antenna arrays can be combined with different microwave signal generation and processing systems for the purpose of accurate measurement. The strength of array technology is its multiple channel measurement which can potentially improve the spatial resolution with $2 \mathrm{D}$ reconstruction.

\subsubsection{UWB Technology}

Driven by the requirements of low power consumption and high resolution, the UWB pulse based measurement has gained significant interest recently. The strength of UWB is the wide frequency bandwidth, where low frequency can obtain a greater penetration depth and high frequency can gain a higher resolution. 
A promising technology is SoC UWB pulse transceiver ICs for time-domain measurement such as XeThruby Novelda, a CMOS chip that delivers high-performance, low-power and miniaturised solutions for impulse radar highperformance sensing and imaging. Novelda NVA6100(Taylor 2012) transceiver operates from 1-10GHz with resolution capability down to $4 \mathrm{~mm}$, and the sampling rate reaches over 30GS/s. These ICs also provide new opportunities for dielectric property measurement, including foodstuffs. The basic function of UWB pulse radar is given in Figure 7.

In terms of signal processing, the UWB Time-Reversal (TR)imaging is a method for remote sensing and imaging applicable for electromagnetics (Moghadasiand Dehmollaian 2014; Yavuz and Teixeira 2006). It explores the TR invariance of wave equation in lossless and stationary media, and provides high resolution and statistical reliability. The TR techniques that rely on UWB operation are further attractive because they can exploit advantages of simultaneous operation at low and high frequencies, and because they enable imaging techniques in random media that dependent only on the statistical properties (Yavuz and Teixeira 2009). TR based remote sensing and imaging in biological and human organ imaging such as breast cancer is widely investigated, and it is also a promising technique for foodstuffs measurement.

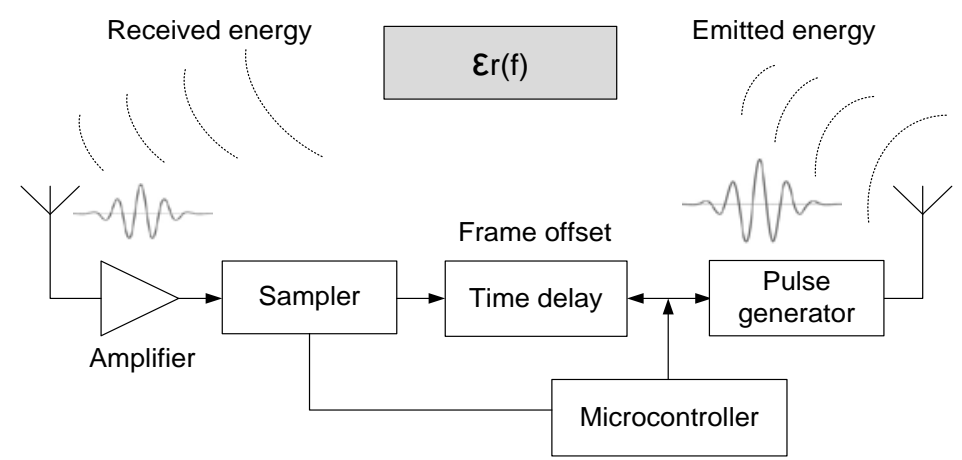

Figure 7. Basic Function of NoveldaSoC Pulse Radar

UWB time domain measurement requires very high-performance microwave circuits for signal generation and data sampling. The clock is strict in order to achievenano-second pulse and tens of GHz data acquisition with Equivalent Time Sampling (ETS). The progress in high-performance MMIC makes it possible to take advantage of UWB technology in low-cost solutions.

\subsubsection{Gain-phase Detection Measurement}

Different from frequency and time domain methods, the gain-phase detection method implements the measurement by detecting variation of electromagneticfields withRF circuits. Then further processing can be performed with the digitised voltage variations interpreting the variations of microwave propagation. Therefore, change in complex dielectric properties of materials will result in measurable signal variations such as gain loss and phase shift.

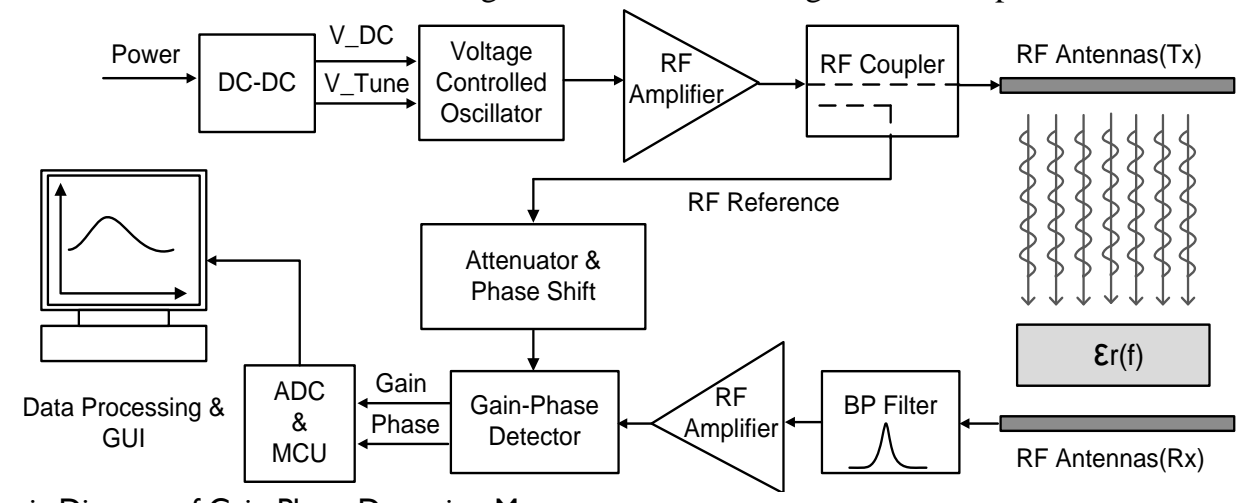

Figure 8. Schematic Diagram of Gain-Phase Detection Measurement

The change in dielectric properties of food material can be determined with gain loss and phase shift obtained by the measurement system. The hardware design of gain-phase detection measurement is discussed in (Mcdermott and Ireland 2004). The system can be extended by applying a linear antenna array for real-time scanning as shown in Figure 8, which can reconstruct the 2D images of moving objects. This is a promising way for practical food production on conveyor belt in industrial applications. With customised designs in both hardware and software, the frame rate of measurement can be high and data interface can be flexible. Therefore, it is more likely to fit the industry and perform on-line measurement.

The above-mentioned techniques can improve the spatial resolution, enhance penetration depth, simplify the system, and reduce cost. They are the enabling technologies for custom designed, miniaturised, high-performance food 
measurement instruments. Most of the existing solutions aim to judge whether there are defects or abnormality in the inspected object, which can be evaluated by extracted features from the received data. However, microwave sensors integrating the emerging techniques can achieve more ambitioustargets, where a complete dielectric image of the object can bereconstructed. The quality of particular food samples can be evaluated with pre-defined models.

\subsection{Microwave Sensor Systems for Future Food Industry}

Some industrial processes nowadays are equipped with smart robotics and sensor modules, which features high quality connectivity, highly adaptive operations, and highly dynamic processes (Körber et al. 2007). The concept of Industrial Internet of Things (IIoT), big data, and a wide range of enabling technologies are introduced to facilitate industrial applications. The connected sensors, controllers, and robotics are open and flexible for data communication and collaboration with connected machines. The recent advancein industry suggests a need for the microwave sensors to be able to suit future industrial application by following the new design concepts.

\section{Conclusion}

This paper gives an overview of the microwave sensor technologies for food measurement, identifies the limitations of the technologies in food measurement, and proposes the potential solutions. In summary, the lessons learned are:

(1) Microwave sensor is sensitive to food quality variation and the wide range frequency is promising to obtain different features, and microwave dielectric measurement is a suitable method for food evaluation due to its nature of contactless, hygienic, and non-destructive.

(2) Most existing microwave measurement methods are for scientific investigation based on lab-instruments such as VNA and impedance analyser, which are bulky, expensive, and inconvenient for on-line measurement in food industry.

(3) Microwave sensor is vulnerable to environmental variations such as electromagnetic interference and temperature, and the size and shape of test samples also contribute to the measurement. Signal processing algorithm and calibration model are major concerns for accurate measurement. But there is no calibration models gaining wide acceptance.

(4) Complexity, hard to calibrate, low spatial resolution, and high-cost are the major limitations of microwave measurement technology. Progresses in MMIC, antenna array, UWB time domain measurement, and Gain-phase detection methods are potential solutions to bridge the gap.

The enabling technologies creates new opportunities for high-performance, miniaturised, and cost efficient microwave sensor modules, which are more suitable for industrial applications. The trend of the future studiesmay focus on the following areas:

(1) Microwave sensors based on low-cost and miniaturised MMICs, UWB technology, and UWB based imaging algorithms will be a solution to improve the spatial resolution and accuracy.

(2) Calibration models of food with different categories, size, and shape are essential to accurate measurement. Integration with other sensor technologies and multi-sensor fusion might be a promising research topic.

(3) Integration of microwave sensor with new emerging ICT technologies for flexible communication and collaborative automation is critical to satisfy the requirements of future industry.

This review covers the theoretical background of microwave measurement, measurement techniques, and calibration methods.The limitations of the applied technologies are identified and emerging technologies that promise potentialsolutions are discussed. The prospect of the proposed promising microwave measurement technologies and new design concepts will be inspirational and of interest to academic, scientific, and industrial community in investigating, developing, and applying the microwave sensor technologies for food measurement.

\section{Declaration of conflicting interests}

The authors declare that there is no conflict of interest.

\section{Funding}

This work was supported by the European Commissionthrough the project PickNPack - Flexible robotic systems for automated adaptive packaging of fresh and processed food products [project code: 311987]. 


\section{References}

Agranovich D, et al. (2016) A microwave sensor for the characterization of bovine milk. Food Control 63,195-200.

Alkhalifeh K, Sarkis R and Craeye C (2012) Design of a novel 3D circular Vivaldi antennas array for Ultra-wideband Near-field radar imaging. In: 6th European Conference on Antennas and Propagation, 898-901.

Austin J, et al. 2014: A novel microwave sensor to determine particulate blend composition on-line. AnalyticaChimicaActa819, 82-93.

Bartley P G, et al. (1998) Determining moisture content of wheat with an artificial neural network from microwave transmission measurements. IEEE Transactions on Instrumentation and Measurement 47(1), 123-126.

Bircan C and Barringer S A (1998) Salt-Starch interactions as evidenced by viscosity and dielectric property measurements. Journal of Food Science 63, 983-986.

Bjarnadottir S G et al. (2015) Assessing quality parameters in dry-cured ham using microwave spectroscopy. Meat science108, 109-114.

Bohigas X, Amigó R, and Tejada J (2008) Characterisation of sugar content in yoghurt by means of microwave spectroscopy. Food Research International 41(1), 104-109.

Casset MessTechnik (2017) Metal detectors. Online: http://cassel-inspection.com/product-category/products/metaldetectors/.

Castro-Giráldez M et al. (2010a) Low-frequency dielectric spectrum to determine pork meat quality. Innovative Food Science and Emerging Technologies 11(2), 376-386.

Castro-Giráldez M, et al.(2010b) Application of microwaves dielectric spectroscopy for controlling pork meat (Longissimus dorsi) salting process. Journal of Food Engineering 97(4), 484-490.

Castro-Giráldez M, et al. (2010c) Microwave dielectric spectroscopy for the determination of pork meat quality. Food Research International 43(10), 2369-2377.

Chandrasekaran S, Ramanathan S, and Basak T (2013) Microwave food processing-A review. Food Research International 52(1), 243-261.

Chen J, et al. (2015) Development of a multi-temperature calibration method for measuring dielectric properties of food. IEEE Transactions on Dielectrics and Electrical Insulation 22(1), 626-634.

Chen L F, et al. (2004) Microwave Electronics - Measurement and materials characterisation. Microwave Electronics, John Wiley \& Sons, Inc.

Cheng E M, et al.(2014) Development of microstrip patch antenna sensing system for salinity and sugar detection in water. Int. J. Mech. Mechatronics Eng. 15(5), 31-36.

Clerjon S, and Damez J L (2007) Microwave sensing for meat and fish structure evaluation. Measurement Science and Technology 18(4), 1038-1045.

Clerjon S, and Damez J L (2009) Microwave sensing for an objective evaluation of meat ageing. Journal of Food Engineering 94(3-4), 379-389.

Daschner F, et al. (2000) Optimization of the microwave determination of water in foods using principal component analysis. In: Proceedings of the 17th IEEE Instrumentation and Measurement Technology Conference, 12-16.

Daschner F, and Knöchel R (2003) Dielectric microwave sensors with multivariate calibration. Advances in Radio Science 1, 9-13.

Decawave (2017) ScenSor DW1000 - Unrivalled indoor precision location and communication numerous market. Online: http://www.decawave.com/products/dw1000.

Fiddes L K, Chang J, and Yan N (2014) Electrochemical detection of biogenic amines during food spoilage using an integrated sensing RFID tag. Sensors Actuators, B Chem. 202,1298-1304.

Gabriel C, et al. (1996)The dielectric properties of biological tissues: I. Literature survey. Physics in medicine and biology 41(11), 2231-49.

Gennarelli G, et al. (2013) A microwave resonant sensor for concentration measurements of liquid solutions. IEEE Sensors Journal 13(5), 1857-1864.

Ghodgaonkar D K, Varadan V V, and Varadan V K(1990) Free-space measurement of complex permittivity and complex permeability of magnetic materials at microwave frequencies. IEEE Transactions on Instrumentation and Measurement 39(2), 387-394.

Gibson A P, et al. (2008) An overview of microwave techniques for the efficient measurement of food materials. Food Manufacturing Efficiency 2(1), 35-43.

Guan D, et al. (2004) Dielectric properties of mashed potatoes relevant to microwave and radio-frequency pasteurization and sterilization processes. Journal of Food Science 69(1), 30-37.

Guo W, et al. (2010) Effects of milk concentration and freshness on microwave dielectric properties. Journal of Food Engineering 99(3), 344-350.

Haq M Z (2002) Applied Measurement Systems. InTech.

Hinz T, et al. (1996) Development of a microwave moisture sensor for application in the food industry. LWT - Food Science and Technology 29(4), 316-325. 
Huang H, Liu L, and Ngadi M O (2014) Recent developments in hyperspectral imaging for assessment of food quality and safety. Sensors 14, 7248-7267

Huang W-D, et al. (2013) A passive radio-frequency pH-sensing tag for wireless food-quality monitoring. IEEE Sensors Journal 12(3), 487-495.

Jackson B and Jayanthy T (2011) A novel method for water impurity concentration using microstrip resonator sensor. In:Proc. Int. Conf. Recent Adv. Sp. Technol. Serv. Clim. Chang, 376-379.

Jha S N, et al. (2011) Measurement techniques and application of electrical properties for non-destructive quality evaluation of foods-a review. Journal of Food Science and Technology 48(4), 387-411.

Jilnai M, et al. (2016) A microwave ring-resonator Sensor for non-invasive assessment of meat aging. Sensors 16(1), 52(1-13).

Karisma A D, et al. (2017) Validation of measured microwave absorption and temperature change for development of a single-mode-type microwave heating thermogravimetry apparatus. Review of Scientific Instruments 88, 024101.

Kent M (1975) Time domain measurements of the dielectric properties of frozen fish. Journal of Microwave Power 10, 37-48.

Kent M (1990) Hand-held instrument for fat/water determination in whole fish. Food Control 1(1): 47-53.

Kent M, et al. (2001) Composition of foods including added water using microwave dielectric spectra. Food Control 12(7), 467-482.

Kent $\mathrm{M}$, et al. (2007) Intangible but not intractable: the prediction of fish "quality" variables using dielectric spectroscopy. Measurement Science and Technology 18(4), 1029-1037.

Kent M, et al. (2000) Determination of prior treatment of fish and fish products using microwave dielectric spectra. European Food Research and Technology 210(6), 427-433.

Kent M, et al. (2002) Determination of added water in pork products using microwave dielectric spectroscopy. Food Control 13(3), 143-149.

Kent M, and Anderson D (1996) Dielectric studies of added water in poultry meat and scallops. Journal of Food Engineering 28(3-4), 239-259.

Khairi M T M, et al. (2016) Contact and non-contact ultrasonic measurement in the food industry: a review. Measurement Science and Technology 27(1), 012001(23pp).

Kim S, et al. (2012) Non-invasive in vitro measurement of pig-blood d-glucose by using a microwave cavity sensor. Diabetes research and clinical practice 96(3), 379-84.

Knöchel R, Daschner F, and Taute W (2001) Resonant microwave sensors for instantaneous determination of moisture in foodstuffs. Food Control, 12(7), 447-458.

Körber H J, Wattar H, and Scholl G (2007) Modular wireless real-time sensor/actuator network for factory automation applications. IEEE Transactions on Industrial Informatics 3(2), 111-118.

Korostynska O, et al. (2013) Real-time microwave based sensing method for vegetable oil type verification. Sensors and Actuators A: Physical 202, 211-216.

Kwok B P, Nelson S O, and Bahar E (1979) Time-domain measurements for determination of Dielectric properties of agricultural materials. IEEE Transactions on Instrumentation and Measurement 28(2), 1-4.

Lee K Y, et al. (2010) In situ measurements of complex permittivity and moisture content in oil palm fruits. The European Physical Journal Applied Physics 49(3), 31201(P1-P5).

Lexa M A, et al. (2015) Using microwave metrology to count calories. Measurement, 65, 11-18.

Matindoust S, et al. (2016) Food quality and safety monitoring using gas sensor array in intelligent packaging. Sensor Review 36(2), 109-114.

Mcdermott B T, and Ireland K (2004) A Low-Cost 100 MHz Vector Network Analyzer with USB Interface. 3-14.

Meng Z, Wu Z, Muvianto C, Gray J (2016) A Data-Oriented M2M Messaging Mechanism for Industrial IoT Applications. IEEE Internet of Things Journal 4 (1), 236-2462.

Moghadasi S M, Dehmollaian M. 2014: Buried-object time-reversal imaging using UWB near-ground scattered fields. IEEE Transactions on Geoscience and Remote Sensing 52(11), 7317-7326.

MoistTech Corp. (2017) Human food moisture applications, Online: http://www.moisttech.com/human-food-moisture/.

Nandhini P, Jaya J, George J (2013) Computer vision system for food quality evaluation - a review. In: International Conference on Current Trends in Engineering Technology, 85-87.

Narsaiah K, Jha S N, Bhardwaj R, Sharma R, Kumar R (2012) Optical biosensors for food quality and safety assurance a review. Journal of Food Science and Technology 49(4), 383-406.

Nelson S O (2006) Agricultural applications of dielectric measurements. IEEE Transactions on Dielectrics and Electrical Insulation 13, 688-702.

Nelson S O, and Stetson L E (1976) Frequency and moisture dependence of the dielectric properties of hard red winter wheat. Journal of Agricultural Engineering Research 21, 181-192.

Ng S K, et al. (2009) Bimodal method of determining fat and salt content in beef products by microwave techniques. IEEE Transactions on Instrumentation and Measurement 58(10), 3778-3787.

Novelda (2017) Respiration monitoring - from treatment to proactive monitoring. Online: https://www.xethru.com/respiration-monitoring.html/. 
Pacquit A, et al. (2006) Development of a volatile amine sensor for the monitoring of fish spoilage. Talanta 69,515-520.

Perten Instruments (2017) In-line NIR sensor -DA 7300. Online: https://www.perten.com/da7300.

Porep J U, Kammerer D. R., Carle R. (2015) On-line application of near infrared (NIR) spectroscopy in food production. Trends in Food Science \& Technology 46, 211-230.

Potyrailo R A, et al. 2012: Battery-free radio frequency identification (RFID) sensors for food quality and safety. J. Agric. Food Chem60(35), 8535-8543.

Pozar D (2005) Microwave Engineering. John Wiley \& Sons, Inc.

Puranik S, Kumbharkhane A, and Mehrotra S (1991) Dielectrics properties of honey-water mixtures between $10 \mathrm{MHz}$ to 10GHz using time domain technique. Journal of Microwave Power and Electromagnetic Energy 26(4), $196-201$.

Schimmer O, et al. (2004) Determination of quality and storage-time of dielectric mixtures using time domain spectroscopy. Advances in Radio Science 2, 1-5.

Schimmer O, Daschner F, and Knochel R (2008)UWB-sensors in food quality management - the way from the concept to market. In: Proceeedings of the 2008 IEEE International Conference on Ultra-Wideband, 141-144.

Schimmer O, et al. (2005) Noncontacting determination of moisture content in bulk materials using sub-nanosecond UWB pulses. IEEE Transactions on Microwave Theory and Techniques 53(6), 2107-2113.

Seifi M R, and Alimardani R (2010) Comparison of moisture-dependent physical and mechanical properties of two varieties of corn (Sc 704 and Dc 370). Australian Journal of Agricultural Engineering1(5),170-178.

Shaji M, and Akhtar M J (2013) Microwave coplanar sensor system for detecting contamination in food products. In: 2013 IEEE MTT-S International Microwave and RF Conference, 1-4.

Shiinoki Y, Motouri Y, and Ito K (1998) On-line monitoring of moisture and salt contents by the microwave transmission method in a continuous salted butter-making process. Journal of Food Engineering 38(2), 153-167.

Sokhansanj S, and Nelson S O (1988) Dependence of dielectric properties of whole-grain wheat on bulk density. Journal of Agricultural Engineering Research 39(3), 173-179.

Tanner, D (2016) Food quality, storage, and transport. Reference Module in Food Science, Online publication: http://dx.doi.org/10.1016/B978-0-08-100596-5.03336-9

Taylor, J D (2012) Ultrawideband Radar Applications and Design. CRC Press.

Trabelsi, S (2013) Investigating effects of aging on radiofrequency dielectric properties of chicken meat. In: 2013 IEEE I2MTC, 1685-1688.

Trabelsi S, and Nelson S O (2003) Free-space measurement of dielectric properties of moist granular materials at microwave frequencies. In: Proceedings of the 20th IEEE Instrumentation Technology Conference, 589-600.

Trabelsi S, and Nelson S O (2016) Microwave sensing of quality food products. IEEE Instrumentation \& Measurement Magazine 19(1), 36-41.

Van Boekel, M A J S (2008) Kinetic modelling of food quality: a critical review. Comprehensive Review in Food Science and Food Safety 7, 144-158.

Venkatesh M S, and Raghavan G S V (2004)An overview of microwave processing and dielectric properties of agri-food materials. Biosystems Engineering 88(1), 1-18.

Wei P J, et al. (2013)Sparse array microwave 3-D imaging: compressed sensing recovery and experimental Study. Progress in Electromagnetics Research 135,161-181.

Weir, W. B. (1974) Automatic measurement of complex dielectric constant and permeability. Proceedings of the IEEE 62(1), 33-36.

Yavuz M E, and Teixeira F. L. (2006)On the sensitivity of time-reversal based techniques to clutter, noise and a class of model perturbations. IEEE Trans. Antennas Propagation 56(3), 834-843.

Yavuz M E, and Teixeira F. L. (2009) Ultra-wideband microwave sensing and imaging using time-reversal techniques: A review. Remote Sensing 1(3), 466-495.

Zhong J, et al. (2016) Coupled electromagnetic and heart transfer ODE model for microwave hearting with temperaturedependent permittivity. IEEE Transactions on Microwave Theory and Techniques 64(8), 2467-2477.

Zhuang H, et al. (2007) Dielectric properties of uncooked chicken breast muscles from ten to one thousand eight hundred megahertz. Poultry science 86(11), 2433-2440.

Zhuge X, and Yarovoy A G (2012) Study on two-dimensional sparse MIMO UWB arrays for high resolution near-field imaging. IEEE Transactions on Antennas and Propagation 60(9), 4173-418. 